\title{
Pharmacognosy and Phytochemical Screening of some Plant Derived Medicine to Treat Dysmenorrheal Pain by the Rajbanshi Community
}

\author{
Priyankar Roy ${ }^{1}$, Palash Mandal ${ }^{1 *}$, Subhasis Panda ${ }^{2}$, Sonia Mitra Roy ${ }^{3}$, Arunika Subba ${ }^{1}$
}

\section{Priyankar Roy', Palash Mandal ${ }^{*}$, Subhasis Panda², Sonia Mitra ${ }^{3}$, Arunika Subba ${ }^{1}$}

'Plant Physiology and Pharmacognosy Research Laboratory, Department of Botany, University of North Bengal, Rajarammohanpur, Siliguri, West Bengal-734013, INDIA. ${ }^{2}$ Department of Botany, Maulana Azad College, 8, Rafi Ahmed Kidwai Rd, Taltala, Kolkata, West Bengal-700013, INDIA.

${ }^{3}$ Himalayan International Residential School, Rajganj, Jalpaiguri, West Bengal-735134, INDIA.

\section{Correspondence}

Dr.Palash Mandal, PhD

Plant Physiology and Pharmacognosy Research Laboratory, Department of Botany, University of North Bengal, Rajarammohanpur, Siliguri, West Bengal-734013, INDIA.

Phone no : +91 9434886123

E-mail:nbubotanypm@gmail.com

History

- Submission Date: 08-03-2018;

- Review Date: 23-03-2018;

- Accepted Date: 03-05-2018

DOI : 10.5530/pj.2018.4.124

Article Available online

http://www.phcogj.com/v10/i4

Copyright

(C) 2018 Phcog.Net. This is an openaccess article distributed under the terms of the Creative Commons Attribution 4.0 International license.

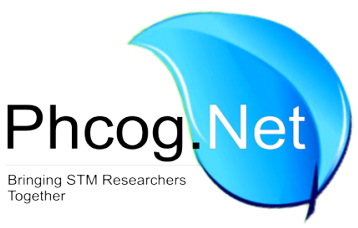

\begin{abstract}
Introduction: Dysmenorrhea is a sort of painful menstrual disorder. Several plants like Allium sativum L., Areca catechu L., Zingiber officinale Roscoe, Crinum amoenum Ker Gawl. Ex Roxb, Cuscuta reflexa Roxb. Nymphaea rubra Roxb. Ex Andrews, Piper nigrum L., Citrus limon (L.) Osbeck were used in appropriate ratio to make herbal formulation to cure dysmenorrheal pain by the traditional healers of Rajbanshi community. Objective: By semi-structured questionnaires in the course of scheduled interviews with the local herbal practitioners, four herbal formulations (coded as DYS1, DYS2, DYS3 and DYS4) were recorded. Pharmacognostic characterization was carried out for the authentication of the powder drugs which includes powder microscopy, fluorescence analysis and physicochemical evaluation. The presence of any therapeutic potential in DYS1, DYS2, DYS3 and DYS4 was determined by qualitative evaluation of phytochemicals of various successive solvent extracts based on their polarity. Thin layer chromatography was performed for screening various phyto-active compounds like arbutin, alkaloids, coumarins, cardiac glycoside, etc. Results: Powder microscopy revealed the presence of calcium oxalate crystal, stone cells etc. Various fluorescence colors were exhibited by these herbal drugs under UV after reacting with chemical reagents. Physical analyses values were also obtained in a satisfactory way. TLC and qualitative phytochemical analysis showed the presence of active phytoconstituents like arbutin, alkaloids, coumarins, cardiac glycoside etc. Conclusion: The results support the use of plants as a traditional medicine for the prevention disorders like Dysmenorrhea. Further evaluation is required for determining the efficacy of those herbal drugs and the active phytoconstituents involved in Dysmenorrheal therapy.

Key words: Dysmenorrhea, Traditional healer, Pharmacognostic evaluation, Antioxidant, Successive solvent extraction, Thin Layer Chromatography.
\end{abstract}

\section{INTRODUCTION}

Plants have created the base of traditional medicine exercised that has been practiced since many years by the people in China, India, and many other countries. Some of the most primitive accounts of the use of the plant as drugs are originated in the Atharva-Veda, which is the origin of Ayurvedic medicine in India. ${ }^{1}$ There is an ancient evidence of medicine discovery on Sumerian clay from Nagpur. Twelve very old medicinal formulation have been reported with plant element such as poppy and Mandrake. ${ }^{2}$ Humans have produced medicine from plants and other organisms for centuries. A good number of the drugs used in modern medicines are formed indirectly from medicinal plants. ${ }^{3}$ and about $90 \%$ of raw resources are derived from the wild sources. However traditional therapy is still restricted to certain areas or group of people because of the unavailability of effective scientific communication. ${ }^{4}$ Therefore the requirement of the significance of herbal medicine and study of the knowledge of traditional healing practices by plants is quite essential. Several active principle constituents are found in those formulations, which could be explained by their function in animal and human system through pharmaceutical and pharmacological study. ${ }^{5}$

Rajbanshis are the fore runner of Koches and are living in Northern Region of West Bengal. Due to a distinctive climatic and ecological provision, a unique Biodiversity hotspot is situated in subHimalayan region of North Bengal. Rajbanshis are dominating this area for many years and they are mostly dependent on agriculture. But socio-cultural activities of the Rajbanshi community are directly and indirectly related to the plant resources. They are using various plant parts to make medicinal formulations for alleviating their diseases \& disorders since time immemorial. ${ }^{6}$ Previously we have found that the herbal practitioners (Kabiraj or Mahan) of Rajbanshi community exercise a total number of 31 types of plant species from 29 genera and 
24 families for preparation of 10 polyherbal formulations to treat various ailments and disorders like arthritis, lesions with pus formation, wound, dysentery, seasonal fever, liver problem, jaundice, nose bleeding along with frequent urination etc. ${ }^{7}$ Our present study revealed that four polyherbal formulations (coded as DYS1, DYS2, DYS3 and DYS4) was made by mixing the various parts of several plants like Allium sativum L., Areca catechu L., Zingiber officinale Roscoe., Crinum amoenum Ker Gawl. ex Roxb., Cuscuta reflexa Roxb., Nymphaea rubra Roxb. ex andrews., Piper nigrum L., Citrus limon (L.) Osbeck. For the said treatment of Dysmenorrhea.

Literature survey did not show any information about pharmacognostic studies of the above polyherbs. For that reason, this study was concentrated on the standardization, by measuring various attributes such as powder microscopy, fluorescence analysis and physicochemical studies to explore the presence of active phytoconstituents and qualitative phytochemicals, extracted from different solvents according to their polarity.

\section{MATERIALS AND METHODS}

\section{Study Area}

Terai and Duars lie in the Northern half of the state of West Bengal and are surrounded by international boundaries of Bangladesh, Nepal and Bhutan. The area is a combination of the wide-ranging landscape - from the high mountainous region in the north to the vast Gangetic plains in the farthest south. The study area lies at $26.7072^{\circ} \mathrm{N}$ and $88.3558^{\circ} \mathrm{E}$. The annual rainfall is recorded to be about $3900 \mathrm{~mm}$ and temperature varies between $7^{\circ} \mathrm{C}$ to $37^{\circ} \mathrm{C}$. The uniqueness of the area has made it one of the treasures of West Bengal with diversified plant and animal populations. The region not only stands out for scenic beauty, along with flora and fauna but also in social atmosphere. The region is a blend of several exclusive tribal communities which makes it rich in culture as well. Some of the major tribes include Rajbanshi, Rabha, Santal, Munda, Oraon, Polia, Lepcha, Toto etc. ${ }^{8,9}$

\section{Collection and authentication of plant material}

Field survey was accompanied with detailed discussions in the form of questionnaires to the medicine men and local people of study areas, as some information was received from them as well. The information includes the mode of consumption, shelf life and ethnic values of the particular plant and its part (s) used. After these detailed discussions, the respective plants were collected properly both in its flowering and fruiting stage. The collected specimens were dried consequently and herbarium sheets were made. Voucher specimen was preserved in the NBU herbarium for further reference.

\section{Sample preparation}

Fresh plant parts are collected from the different part of the study area and dried and make the powder to preserve for future use. Polyhedral powder drugs DYS1, DYS2, DYS3 and DYS4 were prepared according to the herbal healers. The polyhedral powder sample was extracted through soxhlet apparatus in seven different solvents based on their polarity. The solvent extracts were heptane (HP), benzene (BZ), ethyl acetate (EA), acetone (AC), butanol (BT), methanol (MT) and water (AQ). The samples were then evaporated and reconstituted in methanol. These extracted samples were used for qualitative phytochemicals. For TLC and pharmacognostic studies, the samples were used in its powder form.

\section{Pharmacognostic characterization Organoleptic Characters}

The colour, odour, taste and texture of the powder of DYS1, DYS2, DYS3 and DYS4 were observed and recorded.

\section{Anatomy}

Anatomical parameters have been taken into consideration for the study as they are usually the conserved characters for the specific species. The anatomical study revealed some unique and important characteristic features for the studied species. Transverse section of respective part of the studied plant species were done and treated with different reagents i.e. iodine, phloroglucinol and Toluidine blue stain. Iodine stain was used to check the presence of starch grains. Phloroglucinol stains the lignified tissues, whereas Toluidine blue helps to differentiate xylem and phloem cell wall.

\section{Powder microscopy}

The colour, odour, taste and texture of the powder of DYS1, DYS2, DYS3 and DYS4 were observed and recorded..$^{10}$ Microscopic examination was carried out in a standard method. ${ }^{11}$ A small amount of powder of DYS1, DYS2, DYS3 and DYS4 were taken on glass slide, mounted on glycerin and observed under microscope. For the observation of lignified tissues, powder was stained with alcoholic solution of phloroglucinol followed by concentrated $\mathrm{HCl}$. Similarly the powder was also stained with N/10 iodine solution to observe the starch granules and for the identification of fixed oil and fats, Sudan III were used.

\section{Fluorescence analysis}

Fluorescence study of the dried leaf powder was performed using standard procedure. ${ }^{11,12,16} \mathrm{~A}$ small quantity of the sample was treated using fluorescence reagents (such as $1 \mathrm{~N} \mathrm{HCl}, 50 \% \mathrm{H}_{2} \mathrm{SO}_{4}, \mathrm{FeCl}_{3}$, iodine solution, acetic acid glacial, $0.1 \mathrm{~N} \mathrm{NH}_{4} \mathrm{OH}, 1 \% \mathrm{CH}_{3} \mathrm{COOH}$ ). The powder samples after treatment with various chemical reagents were subjected to fluorescence analysis. Observations were made under visible light and under UV light of short $(254 \mathrm{~nm})$ and long wave length $(365 \mathrm{~nm})$ separately. ${ }^{12}$

\section{Physicochemical parameters}

Coarse powder of the plant root was used to perform quality control parameters such as total ash, acid insoluble and water soluble ash, water and alcohol soluble extractive values and loss on drying. ${ }^{13}$ three determinations were carried out for each parameter.

\section{Preliminary phytochemical studies}

The DYS1, DYS2, DYS3 and DYS4 powder extracted in various solvents were subjected for preliminary phytochemical screening to observe the presence or absence of phytoconstituents like tannin, triterpenoids, amino acid, steroids, cardiac glycosides and flavonoids by the standard methods. ${ }^{14-17}$

\section{Thin layer chromatography}

TLC was performed to analyze the variation in bioactive chemical constituents. $^{18}$ Readymade TLC plates (coated with silica gel 60 F254 on aluminum sheets) purchased from Merck Germany were used. The powdered sample was extracted with different procedures for the identification of each of the active constituents i.e. anthraglycosides, arbutin, cardiac glycosides, flavonoids, bitter principles, saponins, coumarins and alkaloids. The mobile phase solvent systems used were ethyl acetate: methanol: water (100:13.5:10) for the detection of anthraglycosides, arbutin, cardiac glycosides, bitter principles and alkaloids. The mobile phase ethyl acetate: formic acid: glacial acetic acid: water (100:11:11:26) was used for flavonoids identification and for the identification of saponin, the solvent system of chloroform: glacial acetic acid: methanol: water (64:32:12:8) was used while for the identification of coumarin, toluene : ethyl acetate (93:7) was used. The developed chromatograms were analyzed for the presence of drug constituents by spraying with suitable group reagent. The chromatograms were then 
observed under UV-254 nm and UV-365 nm light. Photographs were taken with DSLR Nikon camera (D-3200) and the $\mathrm{R}_{\mathrm{f}}$ values were calculated with the following formula:

$$
\mathrm{R}_{\mathrm{f}}=\frac{\text { Distance traveled by solute }}{\text { Distance traveled by solvent }}
$$

\section{RESULTS}

\section{Organoleptic evaluation}

The powder of DYS1, DYS2, DYS3 and DYS4 were brown in colour and rough in texture. DYS1 and DYS4 were slightly bitter in taste, whereas DYS2 and DYS3 were partially sweet in nature. In DYS1, a characteristic pungent smell was observed, as garlic was used in that formulation in appropriate ratio according to the herbal healer's prescription.

\section{Anatomy}

Presence of starch grains were confirmed in species like Citrus limon, Crinum amoenum, Zingiber officinale and Nymphea rubra (Figure 1 A-D). Starch grains were stained with dark blusih-purple colour and were mostly present within the thick walled parenchymatous cells either near the cortex or pith. Starch grains were of various shape and sizes with prominent centered hilum in case of Nymphea rubra. Sclerenchymatous cells occur in patches in Areca catechu, confirmed through phloroglucinol staining (Figure $1 \mathrm{E}$ ). Presence of collenchymatous cells was seen in Nymphea rubra (Figure 1 F). Sclerenchymatous fiber cells were also found in Piper nigrum (Figure $1 \mathrm{~K}$ ). In case of Zingiber officinale, prominent oil glands were observed (Figure $1 \mathrm{~L}$ ). Areca catechu, when treated with toluidine blue stain, showed xylem and phloem wall differentiation along with sclerenchymatous fiber cells embedded within the phloem tissue. The cortical cells of Allium sativum were thick walled and showed prominent differentiation when stained with Toluidine blue (Figure $1 \mathrm{H}$ ). Within the cortical region of Nymphea rubra, some of the cells showed clear wall thickening and could be concluded as islet of sclerenchymatous cells (Figure $1 \mathrm{I}$ ). In case of Piper nigrum fruit coat, presence of thick walled osteosclereides was observed in rows above mesophyll cells (Figure $1 \mathrm{~J}$ )

\section{Powder microscopy}

Powder microscopy has revealed some specific features and helps in authentication of the studied herbal drugs. In case of DYS1, presence of acicular type of calcium oxalate crystals and triangular starch grains with concentric striae were confirmed (Figure $2 \mathrm{~A}$ and B). In DSY2 starch grains of various shapes with central hilum and astrosclereids were observed. Literature showed the presence of astrosclereid in Nymphaeaceae family. ${ }^{19}$ The astrosclereid is usually eight armed with somewhat prominent basal cells, arms are thick without any lumen and were broadbased to narrow tapering ends (Figure $2 \mathrm{C}$ and D). DYS3 revealed the presence of pitted xylem vessels and round shaped uniform starch grains (Figure $2 \mathrm{E}$ and F). In DYS4, elongated stone cells were visible but starch grains were absent (Figure $2 \mathrm{G}$ and $\mathrm{H}$ ). The four formulations have specifically shown the presence and absence of certain features which are significant tools for standardization of these powdered formulations.

\section{Fluorescence analysis}

Different fluorescent colours were exhibited after treating the powdered drugs with different chemical reagents (Figure 3 ). The colours were detected under visible and UV light and were identified by using the standard colour chart of German RAL Institute and noted down in Table 1. Characteristic blue and green colours were observed under UV light when these herbal drugs were interacted with acidic, alkaline or

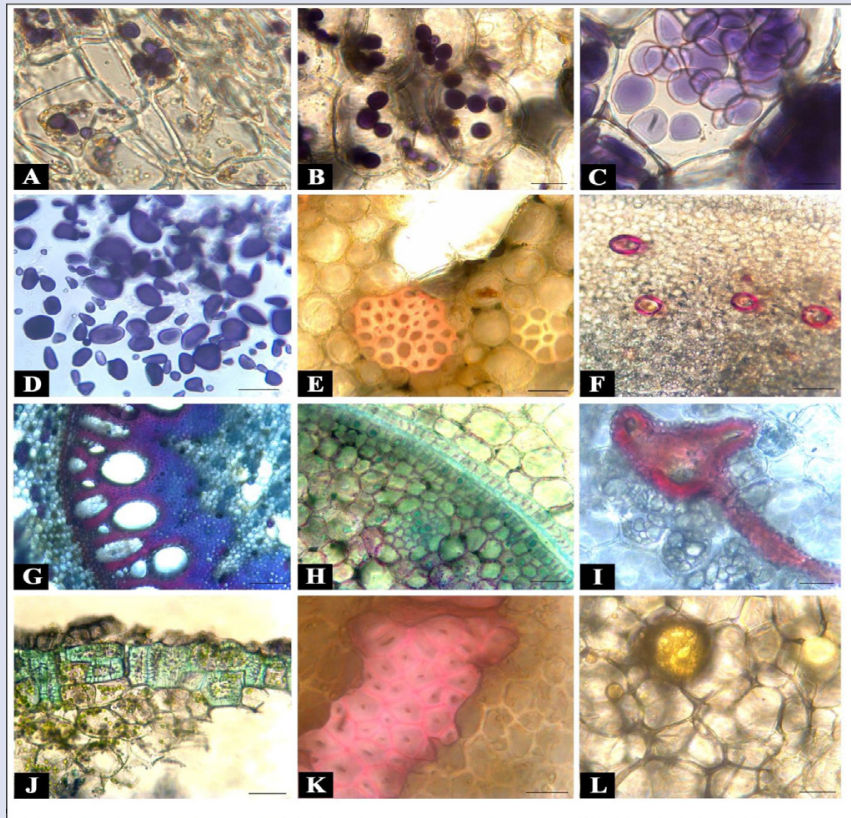

Figure 1. A-D: Starch grain: A. Citrus limon, B. Crinum amoenum; C. Zingiber officinale, D. Nymphaea rubra, E. Sclerenchymatous patch in Areca catechu; F. Collenchymatous cells in Nymphaea rubra; G. Ligning deposition in xylem and sclerenchymatous patches within phloem in Areca catechu; H. Lingnin deposition in cell wall of cortical cells in Allium sativum; L. Sclerenchymatous cells in Nymphaea rubra; J. Lignin deposition in Sclerenchymatous fiber cells in Piper nigrum; K. Sclerenchymatous patch in Citrus limon; L. Oil gland in Zingiber officinale: Scale bar: $330 \mathrm{~min}$ (660x)

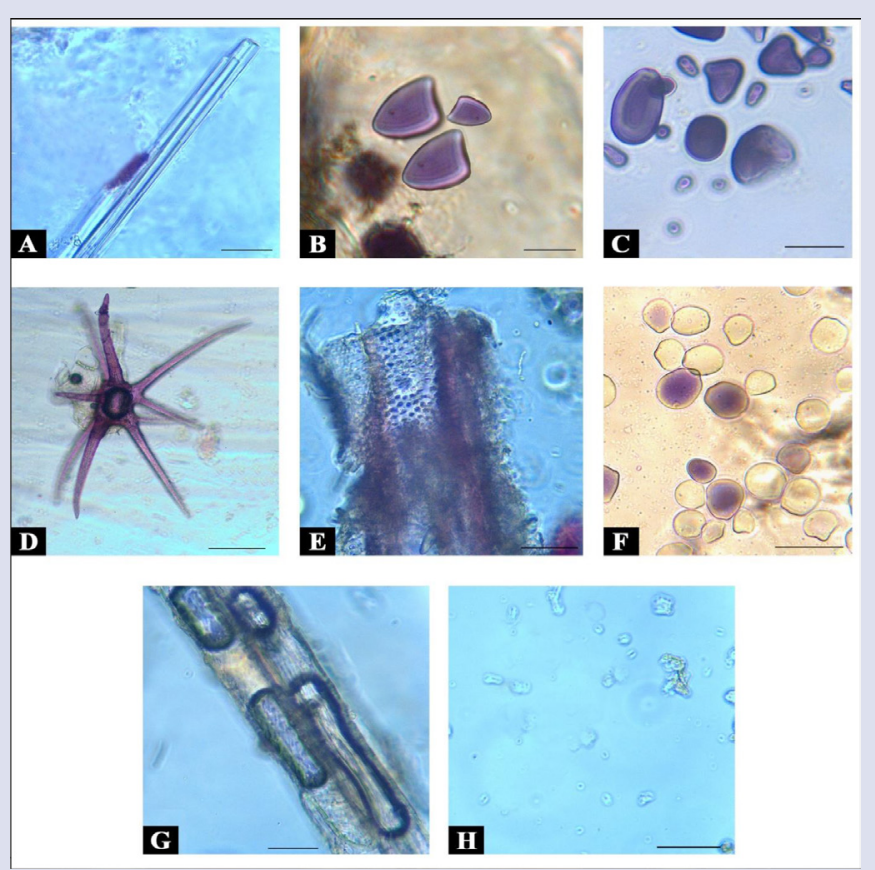

Figure 2. A \& B: DYSI: A. Calcium oxalate crystal, B. Starch grains; C \& D. DYS2: C. Starch grains; D. Abstrosclereid, E \& F. DYS 3: E. Pitted vessels, F. Starch grains; G \& H. DYS4: G. Stone cell, H. Starch grain absent; Scale bar $=330 \mathrm{~mm}$ (660x) 


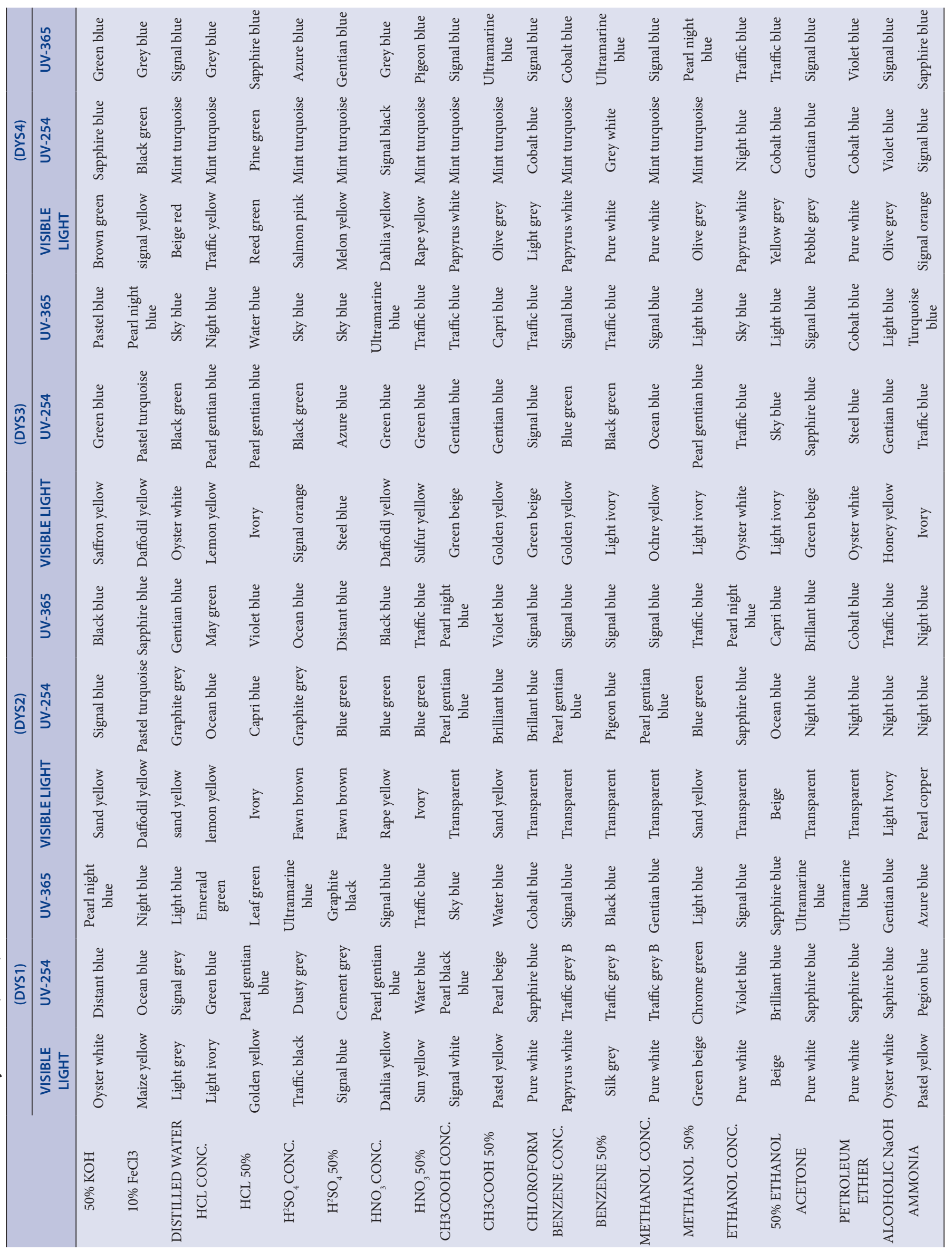


Roy, et al:: Pharmacognosy of Ethnomedicine for Dysmenorrheal Pain

Table 2: Physicochemical analysis of DYS1, DYS2, DYS3 and DYS4

\begin{tabular}{ccccccc}
\hline & $\begin{array}{c}\text { TOTAL ASH } \\
(\%)\end{array}$ & $\begin{array}{c}\text { ACID INSOLUBLE } \\
\text { ASH (\%) }\end{array}$ & $\begin{array}{c}\text { WATER } \\
\text { SOLUBLE ASH } \\
(\%)\end{array}$ & $\begin{array}{c}\text { ALCOHOL } \\
\text { SOLUBLE } \\
\text { EXTACTIVE (\%) }\end{array}$ & $\begin{array}{c}\text { WATER SOLUBLE } \\
\text { EXTRACTIVE (\%) }\end{array}$ & $\begin{array}{c}\text { LOSS ON } \\
\text { DRYING (\%) }\end{array}$ \\
\hline DYS1 & 8.18 & 1.12 & 4.88 & 6.17 & 13.81 & 11.63 \\
DYS2 & 14.63 & 1.37 & 13.47 & 3.87 & 4.64 & 11.53 \\
DYS3 & 20.82 & 8.38 & 19.41 & 4.9 & 4.13 & 8.22 \\
DYS4 & 8.11 & 0.68 & 5.9 & 5.71 & 7.56 & 6.9 \\
\hline
\end{tabular}

organic reagents. In DYS1 nad DYS2, Emerald to leafy green colours were fluoresced in presence of concentrated and 50\% hydrochloric acid respectively. Mineral acids like nitric acid and sulphuric acid produced Traffic Blue and Gentian Blue respectively, when interacting with DYS1 and DYS4. Ammonia showed characteristic Turquoise and Sapphire Blue in response with drug fourmulation DYS3 and DYS4 respectively at UV $365 \mathrm{~nm}$ wavelength. DYS 3 also produced unique blue colours in presence of $50 \%$ acetic acid and methanol reagent.

\section{Physicochemical characteristics}

Total ash is mainly essential to check the purity of drugs showing the presence or absence of metallic salts or silica. ${ }^{20,21}$ the results obtained from physicochemical studies were given in Table 2. Total ash of DYS3 showed the highest value among four herbal drugs, which was found to be $20.82 \% \mathrm{w} / \mathrm{w}$ and DYS 4 confirmed the lowest value of $8.11 \% \mathrm{w} / \mathrm{w}$. The percentage of ash was calculated with reference to the air-dried powder. The acid insoluble ash was noted and DYS3 showed the highest value of $8.38 \%$ and the lowest value of $0.68 \%$ was observed in DYS4. While the presence of material exhausted by water i.e. the water-soluble ash was recorded with high value of $19.41 \%$ in DYS3 and the low value of $4.88 \%$ in DYS1. Purpose of extractive values is a further way of inspection of the purity of the herbal formulation. The water-soluble extractive value was found to be $13.81 \% \mathrm{w} / \mathrm{w}$ which signifies that more amount of constituents in DYS1 was soluble in water than in alcohol $(6.17 \% \mathrm{w} / \mathrm{w})$. The percentage of loss on drying i.e. the moisture content in the powder was found to be $11.63 \% \mathrm{w} / \mathrm{w}$, which is highest in DYS1. In case of DYS4 showed the lowest moisture content.

\section{Qualitative phytochemical analysis}

The biological activity of herbal formulation mainly depends on the phytoactive secondary metabolites present in it. Thus preliminary screening of phytochemicals which was performed to establish a chemical profile of a crude drug was a part of chemical evaluation. ${ }^{22,23}$ these phytochemical tests (Table 3, 4, 5 and 6) revealed the presence of anthraquinones, cardiac glycosides, coumarine, flavonoids and steroids in different extracts of DYS1, DYS2, DYS3 and DYS4 obtained by using different solvents. Alkaloid and amino acid were found only at DYS1 and DYS3. Tannins were absent in all three formulation, except DYS4. In DYS4, soluble tannins were extracted with partial polar to polar solvents. Triterpenoids were found to be present in all formulations, while in DYS4, the same was found in benzene extract only.

\section{Thin layer chromatography}

Initial analysis of active constituents in DYS1, DYS2, DYS3 and DYS4 were carried out by thin layer chromatographic (TLC) method. Following particular spraying reagents for a specific active constituent, the results of TLC showed the presence of arbutin, bitter principle coumarins and saponin in all four formulations. It was found that except DYS2 all formulation showed the presence of anthrone. Anthrone and arbutin bands were most prominent in DYS4. Alkaloid was found only in DYS1 and a clear orange brown band was visible in case of DYS3 under visible light after Dragendorff reagent application. Five band of cardiac glycosides were found only at DYS4, which was clearly distinguishable under visible light, while flavonoids spots on TLC plate was found only in case of DYS2 and DYS4. $\mathrm{R}_{\mathrm{f}}$ values were calculated for all the spot and the analysis were explained at the Table no 7.

\section{DISCUSSION}

There has been a remarkable utilization of herbal formulations in traditional folk medicine for the treatment of diseases and disorders, especially as anti-inflammatory and analgesic agent. ${ }^{24}$ So scientific evaluation is required for each and every formulations mentioned in our traditional indigenous knowledge. ${ }^{25}$ Thus in this study, the pharmacognostic features of these four herbal formulations for primary dysmenorrhea are being reported for the first time.

Therefore, the powder of DYS1, DYS2, DYS3, and DYS4 were subjected to certain standardization parameters. There are numerous modern tools available for the evaluation technique of plant drugs, but powder microscopy is considered to be the most fundamental, authentic, cheap and reproducible methods to recognize the source materials. ${ }^{26}$ Presence of starch granules in DYS2 and DYS3 has been confirmed after staining with iodine solution, whereas phloroglucinol solution showed the presence lignified tissues. Oil globules have been found only in powder DYS3 after staining with Sudan III. Fluorescence study is also an important parameter for standardization of crude drug. The different chemical constituents present in plant extract showed characteristic fluorescence when suitably illuminated. Certain chemical substances that not naturally fluoresce themselves are actually treated with different reagents to attain fluorescence. ${ }^{27}$ the presence of specific amounts of acid, sugar and inorganic matter in the powders are confirmed by water-soluble ash technique, whereas acid insoluble ash methods clearly specify the presence of silica, thus indicating the impurities with earthy materials. ${ }^{28}$ The extractive values are useful to evaluate the chemical constituents present in crude drug and also help for estimation of specific constituents soluble in a particular solvent. For any drugs and herbal formulation, low moisture content is essential for higher stability of drugs. The general requirement for moisture in a crude drug should not be more than $14 \%{ }^{29}$ Excess moisture content may support the growth of fungi and may cause contamination by other microorganisms resulting in the degradation of the drugs. But DYS1, DYS2, DYS3 and DYS4 powder showed the presence of moisture content less than the required standard (Table 2) which was not too high to promote the growth of microorganisms. The pharmacological importance of a drug is attributed to the various secondary metabolites present in it and a particular compound might possess a clinical significance. Therefore it is essential to separate the compounds present in the plants with an appropriate chromatographic method. TLC technique has proved its worth as a simple, inexpensive and reproducible method for the chemical and biological screening of plant extracts. It provides a basic idea of the polarity of a particular chemical constituent. ${ }^{29}$ Development of TLC plates with appropriate group reagents indicate 
Table 3 : Preliminary phytochemical analysis of different solvent extracts of DYS1

\begin{tabular}{cccccccc}
\hline Phytochemical & HP & BZ & EA & AC & BT & MT & AQ \\
\hline Amino acid & - & - & - & - & - & + & - \\
Alkaloids & - & - & - & - & - & - & + \\
Anthraquinones & - & - & - & - & - & - & - \\
Cardiac glycosides & +++ & +++ & ++ & ++ & + & + & + \\
Coumarin & - & - & + & + & + & + & ++ \\
Flavonoids & - & - & - & - & - & - & - \\
Saponins & - & + & ++ & + & + & - & - \\
Steroids & ++ & + & + & ++ & ++ & +++ & ++ \\
Tannin & - & - & - & - & - & - & - \\
Tri-terpenoids & - & - & + & + & - & - & - \\
\hline
\end{tabular}

Table 4 : Preliminary phytochemical analysis of different solvent extracts of DYS2

\begin{tabular}{ccccccccc}
\hline Phytochemical & HP & BZ & EA & AC & BT & MT & AQ \\
\hline Amino acid & - & - & - & - & - & - & - \\
Alkaloids & - & - & - & - & - & - & - \\
Anthraquinones & - & - & - & +++ & ++ & + & - \\
Cardiac glycosides & ++ & ++ & ++ & + & + & ++ & ++ \\
Coumarin & - & - & ++ & ++ & + & ++ & ++ \\
Flavonoids & - & - & ++ & ++ & + & + & + & + \\
Saponins & ++ & + & + & + & + & & - & + \\
Steroids & + & + & + & ++ & ++ & ++ & + \\
Tannin & - & - & - & - & - & & - & -
\end{tabular}

Table 5 : Preliminary phytochemical analysis of different solvent extracts of DYS3

\begin{tabular}{|c|c|c|c|c|c|c|c|}
\hline Phytochemical & HP & BZ & EA & $A C$ & BT & MT & $A Q$ \\
\hline Amino acid & - & - & - & + & - & +++ & ++ \\
\hline Alkaloids & ++ & + & - & - & - & - & - \\
\hline Anthraquinones & - & +++ & ++ & + & - & - & - \\
\hline Cardiac glycosides & +++ & +++ & +++ & ++ & ++ & + & + \\
\hline Coumarin & ++ & +++ & ++ & + & + & ++ & ++ \\
\hline Flavonoids & - & + & - & - & - & - & - \\
\hline Saponins & - & + & + & + & - & - & - \\
\hline Steroids & +++ & +++ & ++ & ++ & + & ++ & +++ \\
\hline Tannin & - & - & - & - & - & - & - \\
\hline Tri-terpenoids & - & - & + & + & + & + & - \\
\hline
\end{tabular}

Table 6 : Preliminary phytochemical analysis of different solvent extracts of DYS4

\begin{tabular}{|c|c|c|c|c|c|c|c|}
\hline Phytochemical & HP & BZ & EA & $A C$ & BT & MT & $A Q$ \\
\hline Amino acid & - & - & - & - & - & - & - \\
\hline Alkaloids & - & - & - & - & - & - & - \\
\hline Anthraquinones & - & + & + & ++ & + & ++ & ++ \\
\hline Cardiac glycosides & ++ & ++ & ++ & ++ & ++ & ++ & ++ \\
\hline Coumarin & - & + & ++ & ++ & ++ & +++ & +++ \\
\hline Flavonoids & - & - & ++ & ++ & ++ & ++ & ++ \\
\hline Saponins & + & + & + & + & - & - & - \\
\hline Steroids & + & + & ++ & +++ & +++ & +++ & ++ \\
\hline Tannin & - & - & + & + & + & + & + \\
\hline Tri-terpenoids & + & + & - & - & - & - & - \\
\hline
\end{tabular}




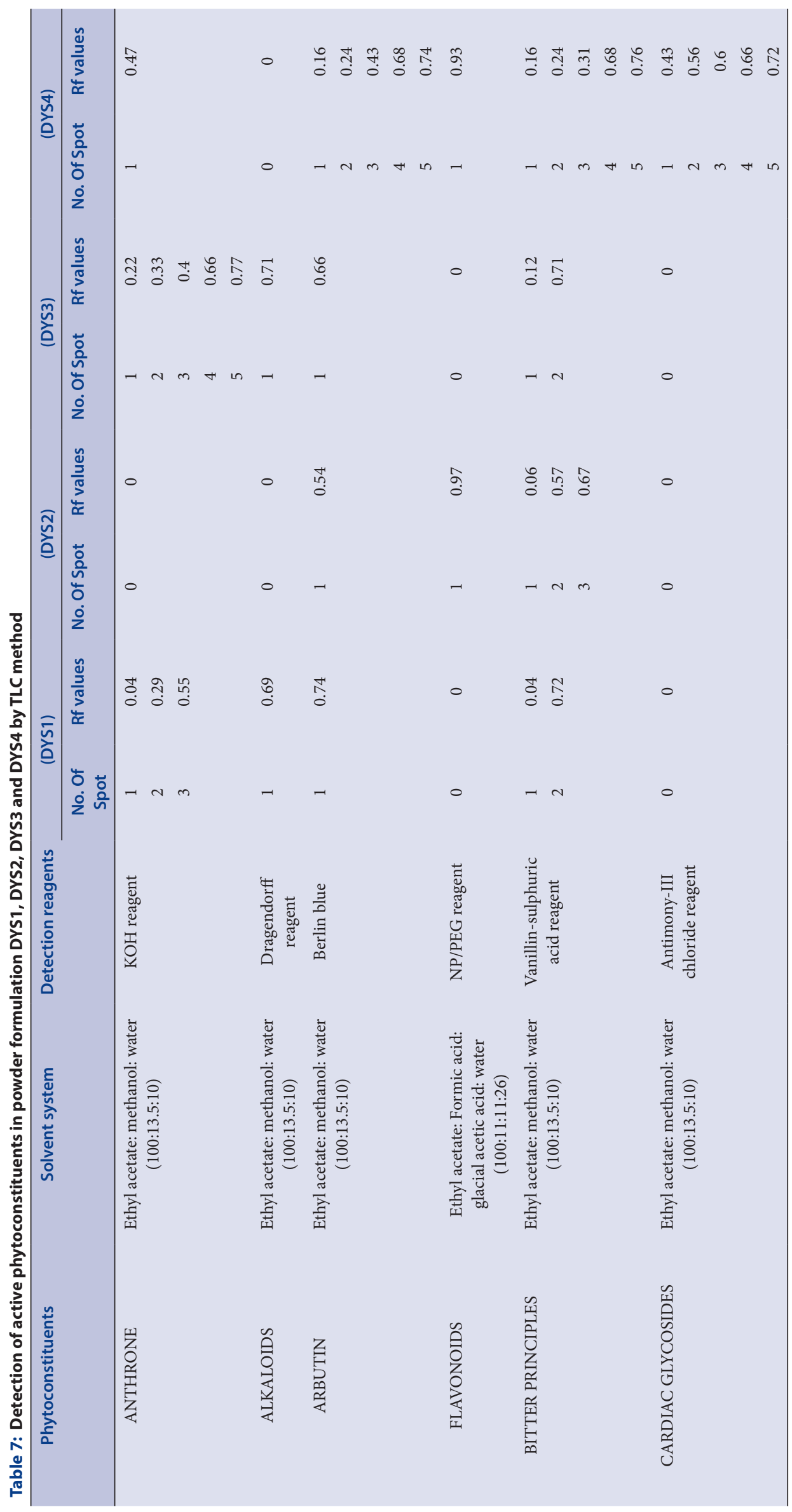




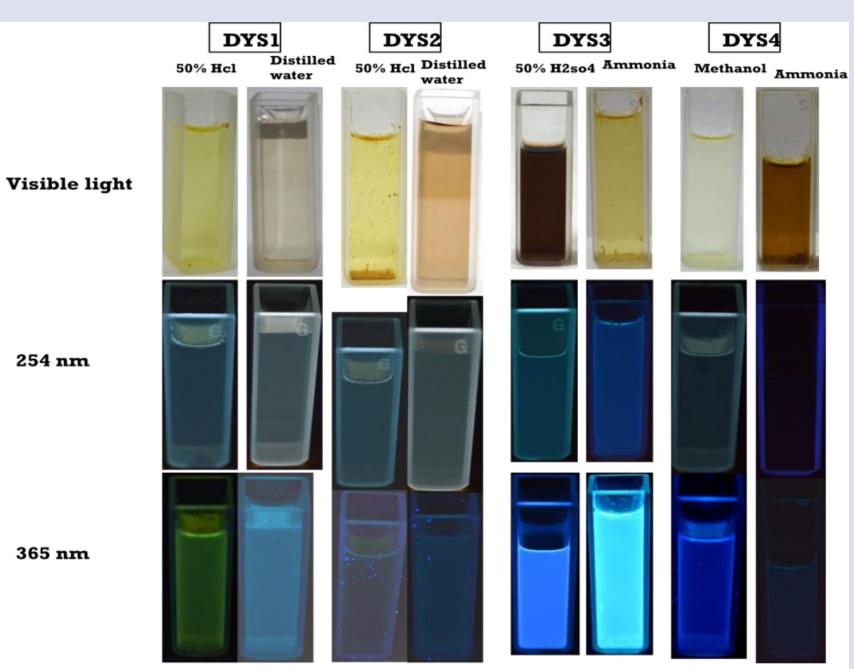

Figure 3: Different colours exhibited after treating the powder of DYS1, DYS2, DYS3 and DYS4 with different chemical reagents.

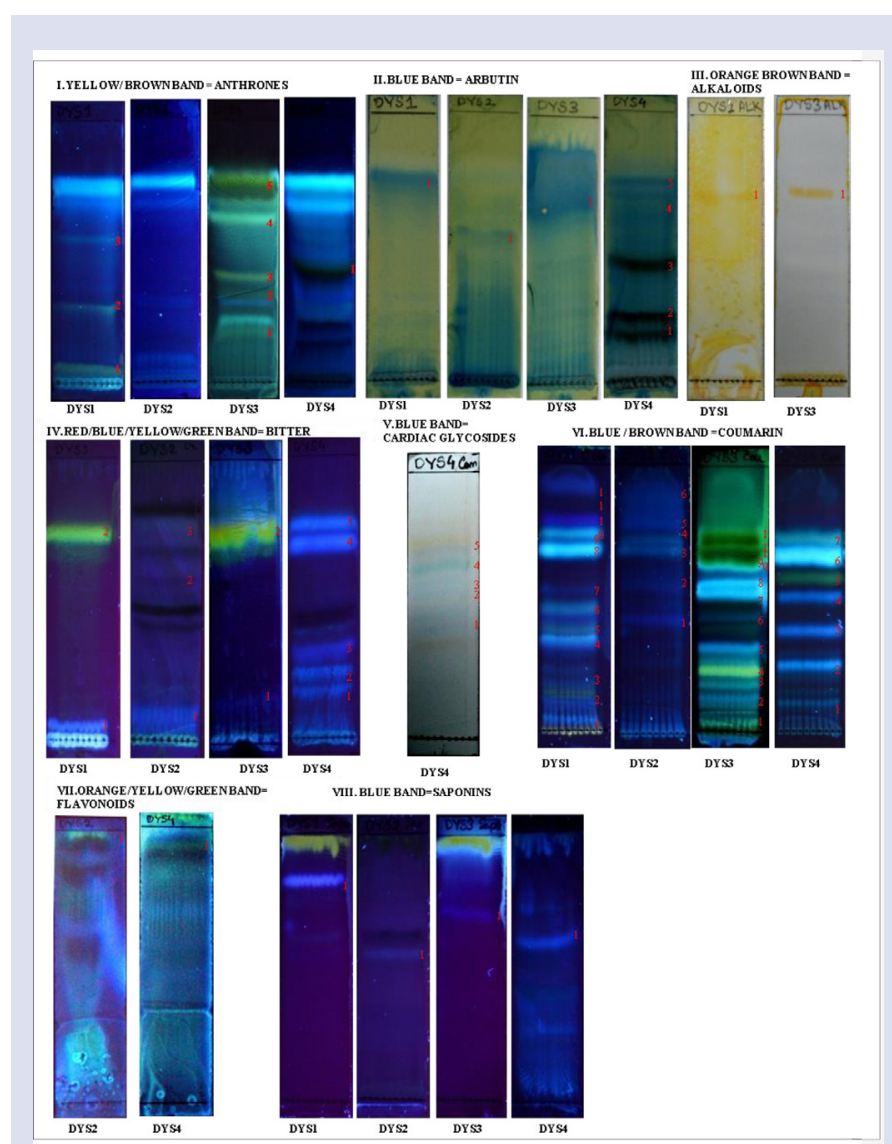

Figure 4: Preliminary investigation by Thin layer chromatography I. Anthrone II. Arbutin III. Alkaloid IV. Bitter Principle V. Cardiac Glycosides VI. Coumarin VII. Flavonoids VIII. Saponins.

the presence of anthrone, arbutin, bitter principle, cardiac glycosides, coumarins, flavonoids and saponins in DYS1, DYS2, DYS3 and DYS4 powder. The pattern of bands on TLC plates provides primary data and is used to show the uniformity and stability of herbal components. It is an effective and speedy way to differentiate between chemical classes which may not be fulfilled by macroscopic and microscopic analysis. ${ }^{30}$
TLC is commonly used for generating fingerprints of herbal medicines as it is simple, versatile, sensitive to specific compounds. ${ }^{31}$ Thus, TLC is a convenient method of determining the quality and possible adulteration of herbal drugs.

Phytochemicals are important for the establishment of pharmaceutical companies; the constituents are playing a significant role in the identification of crude drugs. The medicinal value of these plants lies in some chemical substances that produces a definite physiological action on the human body. ${ }^{33}$ Qualitative phytochemical studies on the different solvent extracts of four herbal formulations revealed that some solvents are good for extraction of phytoconstituents while some others are not suitable. Table no. 3, 4, 5 and 6 showed that the alkaloids and amino acids were found in DYS1 and 3 only. Presence of alkaloid is evidenced by the presence of Dragendorff's band in TLC Plate (Figure 3). All the extracts indicated the presence of cardiac glycoside and steroids in large amount (Table no. 3, 4, 5 and 6). TLC fingerprinting and preliminary phytochemical screening, both proved the presence of coumarin. Coumarins act as competitive inhibitors of vitamin $\mathrm{K}$, which is a blood clotting factor. Coumarins are potent anti-inflammatory drugs and it directs against cell-adhesion molecules, thus highly significant in inflammatory responses. ${ }^{34}$

\section{CONCLUSION}

All the scientific investigations support the traditional use of those powdered polyherbal formulation for the treatment of primary dysmenorrhea. The present study focused on establishing pharmacognostic standards for the identification and authentication of DYS1, 2, 3 and 4, as well as detection of adulterants. The important diagnostic features of all four polyhedral formulations established in this study may be useful for the further studies.

\section{ACKNOWLEDGEMENT}

We are highly obliged to University Grants Commission, New Delhi for providing financial assistance to one of us (P. Roy) for the purpose of studying the traditional healing practices of Rajbanshi community throughout the North Bengal. We are also grateful to the Rajbanshi Community, especially the Mahan / Kabiraj of Rajbanshi community and other resource persons from the Rajbanshi community for extending their help during the field trip.

\section{REFERENCES}

1. Sneader W, Drug Discovery: A History. UK, Wiley, Chichester. 2005.

2. Kelly K. The History of medicine Early Civilizations: Prehistoric Times to $500 \mathrm{CE}$. Facts on File, Inc. An imprint of Info base Publishing 132 West 31st Street New York NY. $10001 ; 2009$.

3. Gangwar KK, Gangwar D, Gangwar RS. Ethnomedicinal plant diversity in Kumaun Himalaya of Uttarakhand, India. Nat Sci. 2010;8(5):66-78.

4. Das T, Mishra SB, Saha D, Agarwal S. Ethnobotanical survey of medicinal plants used by ethnic and rural people in eastern Sikkim Himalayan region. African $J$ Basic and Appl Sci. 2012;4(1):16-20.

5. Dutta SC. Medicinal Plants. New Delhi: National Council for Education Research and Training. 1973

6. S Roy. Ethnobotanical appraisal of Rajbanshi Community of Jalpaiguri and Cooch behar districts of West Bengal, India. J Chem Pharm Res. 2016;8(4):762-6.

7. Roy P, Panda S, Mandal P. Traditional Healing Practices by Some Polyherbal Formulations of Rajbanshi Community. J Chem Pharm Res. 2016;8(10):146-50.

8. Mitra S, Mukherjee SK. Ethnomedicinal usages of some wild plants of North Bengal plains for gastro-intestinal problems. Indian J Tradit. Know. 2010;9(4):705-12.

9. Deka K. Nath N. Traditional Hepatoprotective Herbal Medicine of Bongaigaon District, Assam (NE India) American Journal of Ethnomedicine. 2015;2(5):265-76.

10. Kokate CK, Purohit AP, Gokhale SB. Text book of Pharmacognosy. 18th ed. Pune: Nirali Prakashan. 2002.

11. Lala PK. Practical Pharmacognosy. $1^{\text {st }}$ ed. Calcutta: Lina. 1981.

12. Chase CR, Pratt R. Fluorescence of powdered vegetable drugs with particular 
reference to development of a system of identification. J Am Pharmacol Assoc. 1949;38(6):324-31.

13. Harborne JB. Phytochemical methods-A guide to modern techniques of plant analysis. Berlin: Springer Verlag. 2005

14. Kumar A, llavarasan $R$, Jayachandan $T$, Decaraman $M$, Aravindhan $P_{1}$ Padmanabhan N. Phytochemical investigation on a tropical plant, Syzygium cumini from Kattuppalayam, Erode District, Tamil Nadu, South India. Pak J Nutr. 2009:8(1):83-5.

15. Ngbede J, Yakubu RA, Nyam DA. Phytochemical screening for active compound in Canaruim schweinfurthii (Atile) leaves from los North, Plateau state, Nigeria. Res J Biol Sci. 2008;3(9):1076-8

16. Ibrahim HA, Ibrahim $\mathrm{H}$. Phytochemical screening and toxicity evaluation on the leaves of Argemone mexicana Linn. (Papaveraceae). Int J Pure Appl SciTechnol. 2009;3:39-43.

17. Trease GE, Evans WC. Pharmacognosy. 13 $13^{\text {th }}$ ed. London: Bailliere Tuidal. 1989:799-80.

18. Wagner H, Bladt S. Plant Drug Analysis: A Thin Layer Chromatography Atlas 2nd ed. Berlin: Springer Verlag. 2009

19. Ling-Long Kuo-Huang1, 2, Su-Hwa Chen1, Shiang-Jiuun Chen1. Ultrastructura study on the formation of sclereids in the floating leaves of Nymphoides coreana and Nuphar schimadai. Bot Bull Acad Sin. 2000;41:283-91.

20. World Health Organization. Quality control methods for medicinal plant materials WHO/PHARM/92.559. 1998:4-46.

21. Anonymous. Indian Pharmacopoeia, Vol-II, Ministry of Health and Family Welfare, Govt of India. New Delhi: Controller of Publications. 1996;2:350.

22. Khandelwal KR. Practical pharmacognosy technique and experiments. 23rd ed. Pune: Nirali Prakashan. 2005:149-56.
23. Purohit AP, Kokate CK, Gokhale SB. Pharmacognosy. 13th ed. Pune: Nirali Prakashan. 2005:256-9

24. Amponsah IK, Mensah AY, Otoo A, Mensah ML, Jonathan J. Pharmacognostic standardisation of Hilleria latifolia (Lam.) H. Walt. (Phytolaccaceae). Asian Pac J Trop Biomed. 2014:4(12):941-6.

25. Kumar HD, Mannem K. A comparison study of macroscopical and microscopica characteristics of powder of Haritaki: Terminalia chebula (pericarp), Yavan: Ttrachyspermum ammi (fruit), Ajmoda: Apium leptophyllum (fruit) and Sunthi: Zingiber officinalie (rhizome). Int J Ayurveda Pharma Res. 2012;3(2):309-13

26. Pavanasasivam G, Suktanbawa MU. Flavonoids of some Dilleniaceae species Phytochem. 1975;14(4):1127-8

27. Janchen $D$, Issaq HJ. Modern thin layer chromatography: Advances and perspectives. J Liquid Chromatogr. 1988;11(9-10):1941-65.

28. Ansari SH. Essentials of Pharmacognosy. $1^{\text {st }}$ ed. New Delhi: Birla Publications Pvt. Ltd. 2006:357-83.

29. African Pharmacopoeia. General methods for analysis, $1^{\text {st }}$ ed. Vol 2. Lagos; 1986: 123

30. Dutta J. Phytochemicals analysis and TLC fingerprinting of methanolic extracts of three medicinal plants. Int Res J Pharm. 2013;4(6):123-6.

31. Folashade KO, Omoregie EH, Ochogu AP. Standardization of herbal medicines: A review. Int J Biodivers Conserv. 2012:4(3):101-12.

32. Mohammad A, Bhawani SA, Sharma S. Analysis of herbal products by thin layer chromatography: A review. Int J Pharm Biosci. 2010;1(2):1-50.

33. Ramamurthy $\vee$, Sathiyadevi M. Preliminary Phytochemical Screening of Methanol Extract of Indigofera trita Linn. J Mol Histol Med Physiol. 2017;2(1):1-5.

34. Rohini K, Srikumar PS. Therapeutic Role of Coumarins and Coumarin-Related Compounds. J Thermodyn Catal. 2014;5(2):1-3.

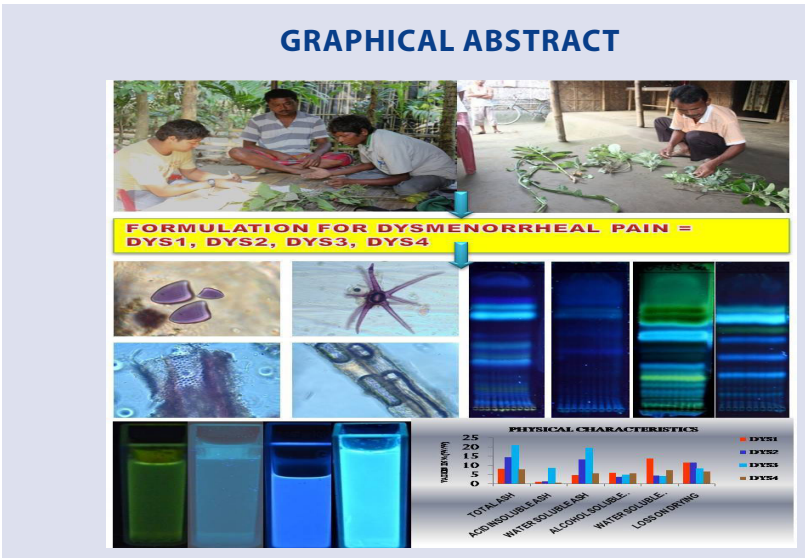

\section{SUMMARY}

Dysmenorrhea is a sort of painful menstrual disorder. By semistructured questionnaires in the course of scheduled interviews with the local herbal practitioners, four herbal formulations were recorded Several plants like Allium sativum L., Areca catechu L., Zingiber officinale Roscoe, Crinum amoenum Ker Gawl. ex Roxb, Cuscuta reflexa Roxb., Nymphaea rubra Roxb. ex Andrews, Piper nigrum L., Citrus limon (L.) Osbeck were used in appropriate ratio to make herbal formulation to cure dysmenorrheal pain by the traditional healers of Rajbanshi community. The present research article focuses on the evaluation of pharmacognostic identity and quality parameters to be used as herbal drug and thus validating its ethno-medicinal use to treat Dysmenorrhea.

\section{ABOUT AUTHORS}

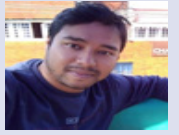

Mr. Priyankar Roy: Is a senior research fellow at the Department of Botany, University of North Bengal under the Basic Scientific Research scheme, UGC. He has 5 publications and his doctoral research is focused on the Pharmacognostic evaluation of herbal medicines used by traditional healers of Rajbanshi community in Terai \& Duars region of West Bengal, India.

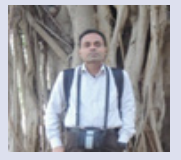

Dr. Subhasis Panda: Is an Associate Professor at Department of Botany, Maulana Azad College, University of Calcutta. Earlier in PG Deptt. of Botany, Barasat and Darjeeling Govt. Colleges. Also KS Manilal National Awardee in Angiosperm Taxonomy. Discovered 12 new plant species. Earlier he was Research Fellow in Central National Herberium (1999-2003).

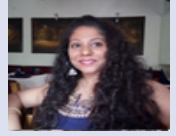

Dr. Mrs. Sonia Mitra Roy: Is an Assistant teacher of Biology at Himalayan International Residential School, Rajganj, Jalpaiguri, West Bengal, India. She has 7 publications and completed her doctoral thesis on "Foliar Architecture of Indian members of the Family Sterculiaceae and its Systematic Relevance".

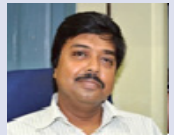

Dr. Palash Mandal: Is an Assistant Professor at the Department of Botany, University of North Bengal, West Bengal, India. His research interest is in the area of Plant Physiology and Pharmacognosy. He has 70 nos. of research publications; 15 nos. of abstracts and 4 nos. of book chapters. He is having 17 years of teaching experience at North Bengal University and guiding many post graduate and doctoral students. Currently he is working on bioactivities of plant peptides; therapeutic potential of various ethnomedicine.

Cite this article: Roy P, Mandal P, Panda S, Mitra S, Subba A. Pharmacognosy and Phytochemical Screening of some Plant Derived Medicine to Treat Dysmenorrheal Pain by the Rajbanshi Community. Pharmacog J. 2018;10(4):738-46. 